\title{
A SOCIOLOGIA DA EDUCAÇÃO E O ESTADO APÓS A GLOBALIZAÇÃO'
}

ROGER DALE*

\begin{abstract}
RESUMO: Em The State and education policy (1989) argumentava que (1) os sistemas de educação e as políticas educacionais, ${ }^{1}$ enquanto partes do Estado, eram moldados pela sua contribuição à solução de três condições de existência "centrais" do capitalismo (o apoio infraestrutural ao processo de acumulação, a construção da ordem social e a legitimação do sistema) e (2) as "soluçōes" para esses problemas tendiam a ser mutuamente contraditórias, sendo essas contradições os principais motivadores das políticas de educação. Desde então, as formas desses problemas centrais e do "estado" têm mudado fundamentalmente em razão da "constitucionalização do neoliberal", da fusão da regulação e da emancipação, da mudança de governo para governança e da reconstrução e recontextualização do "nacional". Isto exige que repensemos os modos como a sociologia da educação aborda conceitos como "nacional", "educação" e "sistemas".

Palavras-chave: Estado. Problemas centrais do capitalismo. Políticas educacionais. Governança educacional. Nacionalismo metodológico.
\end{abstract}

\section{THE SOCIOLOGY OF EDUCATION AND THE STATE AFTER GLOBALISATION}

ABSTRACT: In The State and education policy (1989) I argued that (1) education systems and education policy, as parts of the state, are shaped by their contribution to the solution of three fundamental "core" conditions of existence of capitalism ("infrastructural" support for the accumulation process, the construction of social order,

* Proferido no II Seminário de Educação Brasileira, na Universidade Estadual de Campinas (UniCAmp), no dia $1^{\circ}$ de dezembro de 2009. Tradução de Alain François.

** Professor da Universidade de Bristol (ESRC LLAKES Centre). E-mail: r.dale@bristol.ac.uk

Educ. Soc., Campinas, v. 31, n. 113, p. 1099-1120, out.-dez. 2010

Disponível em <http://www.cedes.unicamp.br> 
and the legitimation of the system), and (2) the "solutions" to these problems were likely to be mutually contradictory, with these contradictions major drivers of the politics of education. Since then, the forms of the core problems, and of the "state", have changed fundamentally in terms of the "constitutionalisation of the neoliberal", the fusing of regulation and emancipation, shifts from government to governance, and the reconstruction and recontextualisation of "the national". This calls for a major rethinking of the ways sociology of education approaches concepts such as "national", "education", "systems".

Key words: State. Core problems of capitalism. Education policy. Education governance. Methodological nationalism.

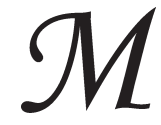

inha meta aqui é examinar tanto a relação entre a globalização e o Estado quanto à relação entre a globalização e a sociologia da educação. Sendo a primeira claramente mais importante, quero propor que os modos como a entendemos estão vinculados às ferramentas teóricas e metodológicas que usamos para chegar a tal compreensão. A questão fundamental é saber se a globalização representa "alguma coisa nova, distinta e diferente", uma quebra ou ruptura com o que veio antes, ou se se trata de uma continuidade, embora com diferenças bem drásticas em relação ao que conhecíamos antes. Para tratar essa questão, vou revisitar o meu livro The State and education policy ( $O$ Estado e as políticas educacionais), publicado 20 anos atrás (Dale, 1989), indagando o quanto a abordagem então adotada ainda é válida nas atuais circunstâncias, alteradas pela globalização, e que mudanças poderiam ser necessárias para ajudar o nosso entendimento sobre a relação entre globalização e educação.

Em The State and education policy, a essência do argumento era que o capitalismo não conseguia providenciar suas condiçóes de existência extraeconômicas com os próprios recursos e, portanto, precisava do Estado para isso. Mais particularmente, enfrentava três "problemas centrais": garantir uma infraestrutura para a acumulação contínua e o desenvolvimento econômico, tal como a disponibilização de uma mão de obra diversamente qualificada; assegurar um nível de ordem e coesão sociais; legitimar as desigualdades inerentes ao sistema. Sempre argumentei que as soluçôes para esses problemas eram, provavelmente, tão mutuamente contraditórias quanto complementares (a maneira 
como os estudantes são separados em função das suas habilidades [streaming] é um bom exemplo disso: alega-se que melhora a identificação e o desenvolvimento da força acadêmica e, assim, contribui para o objetivo de acumulação, mas, ao mesmo tempo, é amplamente considerada como injusta e, portanto, como uma ameaça contra o objetivo de legitimação) e que as tentativas para resolver essas contradições constituem o fulcro das políticas educacionais. Essencialmente, esses problemas podem ser vistos como definindo os limites do possível para os sistemas educacionais, não no sentido de que exigem currículos particulares (o capitalismo mostrou que pode muito bem conviver com um leque de diferentes preferências e movimentos sociais, como o feminismo, por exemplo, e com uma ampla gama de sistemas educacionais distintos), mas no sentido de que estipulam o que não é do interesse do capital. Esses limites são dificilmente previsíveis e costumam ser reconhecidos apenas quando são rompidos, mas a sua realidade é reforçada pela crescente mobilidade do capital, a qual permite mudar rapidamente de regime educativo, caso se considere que este não oferece apoio suficiente.

Começarei afirmando que, na sociologia da educação, a maioria das respostas à globalização adota abordagens que veem uma "continuidade", não uma "ruptura”. Nelas, a globalização é considerada como mais um efeito externo, possivelmente mais expressivo, sobre os sistemas educacionais nacionais. Existem dois problemas importantes com essas abordagens. Primeiro, o status explicativo da "globalização" lembra o do "fordismo", por exemplo, quando nos perguntávamos que mudanças acarretara para as escolas. Além do mais, existe, nessas abordagens, uma tendência a teorizar a globalização de modo muito frouxo, pois não faz distinções entre a sua representação como discurso: "é tudo globalização"; como processo (e geralmente como processo sem agente); como situação, como a "Mcdonaldização"; como convergência envolvente (mesmo se convergência do que e em que período é raramente especificado); ou, muito menos, como processo político, impulsionado por interesses particulares.

O segundo problema é o foco principal, nesses trabalhos, sobre os "efeitos” da globalização nos sistemas educacionais e nas escolas nacionais internas. Esta é obviamente uma questão importante, mas que, de modo algum, esgota as possibilidades da relação entre globalização e educação. Poderia, por exemplo, ser tomada como algo que implica uma relação exclusivamente "de cima para baixo" ou unidirecional entre a 
globalização e os Estados-nações. Contudo, esta não é, sem dúvida alguma, a única forma de relação; desvia, por exemplo, a atenção da possibilidade de efeitos em níveis outros que não o nacional (o que é estranho para uma abordagem intrinsecamente extranacional). Além disso, os próprios Estados (pelo menos os ocidentais), longe de serem vítimas mais ou menos indefesas da globalização, estão entre seus agentes mais fortes e são participantes condescendentes e conscientes ou parceiros na relação com os outros agentes da globalização (especialmente outros Estados, com os quais celebram acordos que a impulsionam). Além disso, existem outros quatro argumentos a respeito das questões teóricas e metodológicas envolvidas na abordagem "efeitos sobre". Primeiro, os próprios "efeitos" são muito mais amplos do que se costuma pensar. Em essência, limitam-se à primeira dimensão de poder de Lukes e influenciam as decisōes a serem tomadas, tendo muito pouco a dizer sobre poder de agenda ou formação da preferência. Segundo, pode-se esperar que qualquer "efeito" seja diferente em Estados diferentes, e seja interpretado de acordo tanto com a concepção do supranacional vigente quanto com as próprias interpretaçóes das agendas estabelecidas naquele nível; em outras palavras, o "nacional" e o "supranacional" devem ser problematizados. Terceiro, a relação entre escalas não se limita a "efeitos" de uma sobre a outra, mas pode mais efetivamente ser abordada como uma divisão de trabalho funcional, escalar e setorial (ver a seguir). E quarto: a abordagem tende a levar a tentativas de quantificação dos efeitos da globalização. De novo, nada há de errado nisso, mas, como sabemos, existe uma tendência, nessas abordagens, a ignorar qualquer coisa que não se possa quantificar.

A base do argumento da "ruptura" pode ser formulada muito brevemente: o estado atual da educação, como de outras instituições da modernidade, é fundamentalmente um reflexo de e uma resposta à natureza variável da relação entre capitalismo e modernidade. Ao desenvolver o argumento fundamental, sigo Boaventura de Sousa Santos, pois sugiro ser crucial, para entender os atuais predicamentos globais, distinguir as trajetórias do capitalismo (que se apresentam atualmente na forma da globalização neoliberal) e da modernidade e examinar as relações entre ambas. Como diz Santos,

A modernidade ocidental e o capitalismo são dois processos históricos diferentes e autônomos... [que] converteram-se e entrecruzaram-se (...). 
Estamos vivendo um momento de transição paradigmática e, consequentemente, o paradigma sociocultural da modernidade (...) desaparecerá provavelmente antes de o capitalismo perder a sua posição dominante (...). Esse desaparecimento (...) é simultaneamente um processo de superação e um processo de obsolescência. É superação na medida em que a modernidade cumpriu algumas das suas promessas, nalguns casos até em excesso. É obsolescência na medida em que a modernidade já não consegue cumprir outras das suas promessas. (2002, p. 1-2)

E continua o autor: "A modernidade baseia-se em uma tensão dinâmica entre o pilar da regulação (o qual garante a ordem numa sociedade existente em um determinado momento e lugar) e o da emancipação: a aspiração por uma boa ordem em uma boa sociedade, no futuro" (idem, p. 2). A regulação moderna é "o conjunto de normas, instituições e práticas que garante a estabilidade das expectativas" (ibid.); o pilar de regulação é constituído pelos princípios do Estado, o mercado e a comunidade (tipicamente considerados como os três agentes-chave da governança (ver Dale, 1997). A emancipação moderna é o "conjunto de aspirações e tendências opositivas que visam aumentar a discrepância entre as experiências e as expectativas" (ibid.). É constituída por "três lógicas de racionalidade (...): a racionalidade estético-expressiva da arte e da literatura; a racionalidade moral-prática da ética e do direito; e a racionalidade cognitivoinstrumental da ciência e da técnica" (p. 3). Contudo,

(...) o que caracteriza mais fortemente a condição sociocultural no início do século é o colapso do pilar da emancipação no pilar da regulação, fruto da gestão reconstrutiva dos excessos e dos déficits da modernidade, que (...) foram considerados (...) como deficiências temporárias, qualquer deles resolúvel através de uma maior e melhor utilização dos crescentes recursos materiais, intelectuais e institucionais da modernidade (...) [e] que tem sido confiada à ciência moderna e, em segundo lugar, ao direito moderno. (p. 4-5, 7)

Além do mais, esses dois pilares, hoje em dia, deixaram de estar em tensão e estão quase fundidos, como resultado da "redução da emancipação moderna à racionalidade cognitivo-instrumental da ciência e a redução da regulação moderna ao princípio do mercado" (p. 9). Podemos resumir esses argumentos propondo que significam que a modernidade não é mais o melhor invólucro possível para o capitalismo, em sua forma neoliberal global. 
Além do mais, e igualmente crucial para o Estado, temos o desenvolvimento da forma política do neoliberalismo, geralmente chamada de Nova Gestão Pública, que tem como uma das suas característicaschave o fato de, em conformidade com o neoliberalismo, não funcionar contra o Estado, mas através dele. Isso foi chamado de constitucionalização do neoliberal, por meio do "movimento para construir dispositivos legais ou constitucionais que ocultem ou isolem consideravelmente as novas instituiçōes econômicas do exame popular minucioso ou da responsabilidade democrática" (Gill, 1992, p. 165).

A história recente da universidade pode ser tomada como exemplo perfeito do tipo de fusão da emancipação e da regulaçãa à qual Santos se refere. Historicamente, a educação tem sido associada aos dois pólos, um fato que está na base de muitas das tensōes de que ela sofre. Em particular, as mudanças na educação podem ser vistas como formas de "gestão reconstituinte" dos déficits da modernidade. Assim, as consequências dessas mudanças não são vistas como transcendendo a modernidade, mas como um uso intensificado das ferramentas da modernidade, que produzem o que pode ser considerado como uma forma de ultramodernidade, especialmente através das mudanças de escalas de identificação e de resolução dos problemas. Propomos que, embora nem a extensão nem o resultado desses processos ainda sejam definidos, (a) está claro que esses resultados têm uma natureza mais contingente do que determinada; (b) não podem ser encontrados apenas em nível nacional; e (c) devem provavelmente ser caracterizados não apenas por fusão, hibridez ou convergência, mas por uma divisão funcional e escalar do trabalho entre discursos paralelos.

Em termos de relevância para o Brasil, recorro à referência de Paul Cammack (2004, p. 266) à "evidência de uma guinada marcada, na região, rumo à busca sistemática por competitividade internacional". Ele distingue três aspectos associados da reorganização interna do Estado na América Latina: a internalização da competitividade internacional "como objetivo central para mediar entre a territorialização da produção de valor e a dependência crescente da circulação internacional" (idem, ibid.), a busca de uma "estratégia redistributiva da austeridade competitiva" e a "internacionalização dos aparelhos do Estado para mediar a extensão e a intensificação do mercado mundial", através da "regionalização e da reforma liberal da regulação global" (idem, ibid.). Ele aponta para: 
O surgimento, na América Latina, de uma série de projetos nacionais, regionais e internacionais voltados para o "desenvolvimento orientado pelo mercado e baseado na concorrência internacional", (...) que busca internalizar, em nível nacional, a lógica da reprodução capitalista e a hegemonia burguesa (...), confirmando enfaticamente a centralidade do Estado na reprodução do capitalismo contemporâneo, assim como a influência de um conjunto de instituições internacionais, entre as quais a União Europeia desempenha um papel significativo. O projeto global que emerge disto tem uma característica notável: visa a generalizar as relaçóes sociais constitutivas do capitalismo no mercado mundial como um todo e, ao mesmo tempo, a conter os antagonismos que lhe são inerentes, sobretudo na sua preocupação em tornar hegemônicas as novas burguesias que promove. (idem, ibid.)

Mas o que isso significa para o argumento dos problemas centrais? Ainda temos o capitalismo, o Estado e "políticas educacionais"; nenhum deles sumiu (embora possa haver quem não concorde com isso no caso das políticas educacionais). A primeira coisa a se dizer é que o capitalismo continua dominando como antes e com tanta necessidade de garantir as suas condições de existência quanto antes. Sendo assim, dois conjuntos de perguntas tornam-se centrais para podermos considerar as implicações para a educação: qual a forma dos problemas centrais e qual a forma do Estado, sob a globalização?

Muito brevemente, podemos dizer que, sob o regime anterior, a relação entre o capitalismo e os problemas centrais era mediada pela ideia de que os piores efeitos do capitalismo tinham de ser compensados por uma ação do Estado. Isto significava uma ênfase na legitimação e na coesão societais, nas quais a educação estava centralmente envolvida, particularmente na primeira, pois a função de seleção e triagem da educação era crucial para persuadir aqueles que estavam em baixo da pirâmide social de que o seu fado se devia a sua própria inadequação, revelada pelo seu desempenho escolar, não à injustiça inerente ao capitalismo enquanto sistema. Essa ordem de prioridades foi invertida sob a globalização neoliberal, na qual a "competitividade" se tornou a característica dominante, a educação estando profundamente implicada em consegui-la. Isto levou à predominância do problema da acumulação (tal como encontrado, por exemplo, na ênfase onipresente sobre a "Economia do Conhecimento" e discursos associados).

Finalmente, o próprio Estado foi transformado pela introdução da Nova Gestão Pública, cujos efeitos são representados graficamente 
na figura a seguir. Não é mais apenas um Estado nacional, nem um Estado executivo eficiente, mas continua sendo o coordenador em último recurso, e o lugar para onde se dirigir quando os outros agentes de governança falham (como vimos em muitos casos de fracassos de parcerias público-privado, por exemplo). E continua sendo o único recurso quando os problemas centrais parecem não estar resolvidos (e os acontecimentos dos dois últimos anos devem certamente ter convencido do contrário os que duvidavam dessa última alegação).

\section{Figura 1}

Governança educacional multiescalar

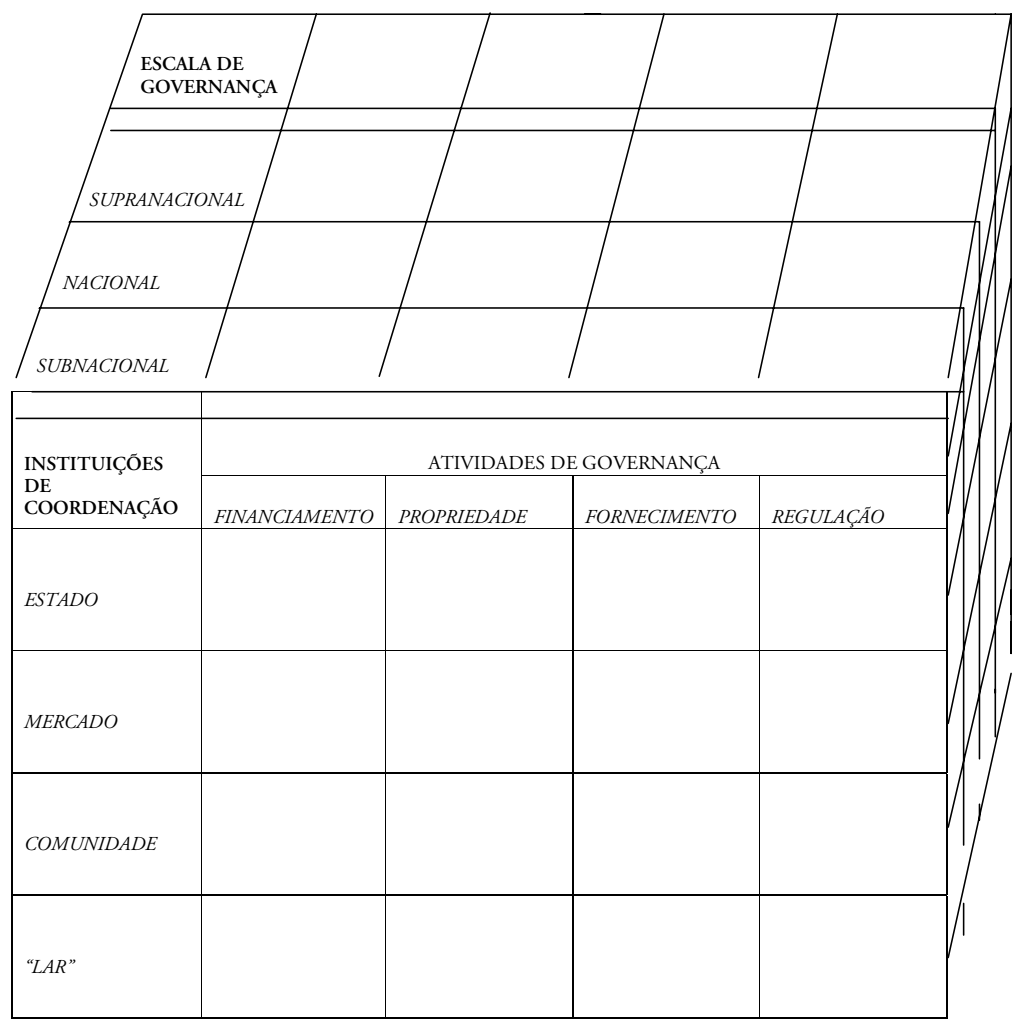


Contudo, não se trata apenas de uma questão de "aplicar" aqueles conceitos numa era diferente. E este é um dos maiores problemas metodológicos das ciências sociais: as palavras continuam as mesmas, mas os seus significados mudam. Isso foi muito bem formulado pelo antropólogo Gavin Smith (2006, p. 628): "Muitos conceitos-chave para compreender a sociedade tiram o seu poder do fato de parecerem ser apenas o que sempre foram e a sua instrumentalidade do fato de assumirem formas bem diferentes". Esta ideia é extremamente crucial. Por um lado, significa que aquilo que chamamos de "currículo", ou de "estado", por exemplo, pode não se parecer muito com o que essas palavras designavam 20 anos atrás. Isto tem consequências enormes para a sociologia da educação depois da globalização. Essencialmente, permite-lhe continuar "como se nada tivesse acontecido" e virar a sua atenção para as maneiras como a globalização opera enquanto outro efeito qualquer, embora poderoso e complicado, sobre sistemas, políticas e práticas educacionais existentes.

Por outro lado, isso nos expõe ao que Roberto Mangabeira Unger (1998) chama de "fetichismos": "limites à nossa habilidade de imaginar e mudar a sociedade". Existem dois tipos: o institucional, que é a "identificação de concepções institucionais, tal como a democracia representativa, uma economia de mercado, e uma sociedade civil livre, com um único conjunto de arranjos institucionais", e o estrutural, "que encontra a sua expressão e a sua defesa numa ideia que opõe interlúdios de efervescência, carisma, mobilização, e energia ao reino corriqueiro da rotina institucionalizada, quando, meioadormecidos, continuamos seguindo o roteiro escrito nos intervalos criativos" (Unger, 1998, p. 26).

$\mathrm{O}$ que isso envolve, crucialmente, está perto do que Santos chama de ineficiência das ferramentas da modernidade para enfrentar os problemas da pós-modernidade. Mais significativamente, a globalização tem abalado a suposição central de que "a educação" ocorre em "sistemas" "educacionais" "nacionais", com consequências enormes para a área de estudo, tanto metodológicas quanto "políticas". Esses três elementos centrais correm o risco de se tornarem um tanto engessados e de logo restringirem, ou até mesmo obstruírem, as nossas oportunidades de enfrentar a globalização e os modos como a vida institucional e cotidiana foi transformada, em vez de expandi-las. 
Quanto ao primeiro termo, "nacional”, a globalização transformou a ideia de que a educação ocorre apenas em sistemas nacionais instaurados para tanto. O lugar e a força dos Estados nacionais foram amplamente alterados, com uma consequência muito expressiva para uma sociologia da educação que partiu do princípio de que a base da "educação" é nacional. Descrevi a forma que essas consequências assumem como "-ismos" metodológicos, respectivamente nacionalismo metodológico, estadismo metodológico e educacionismo metodológico. Em cada caso, o "-ismo" é usado para sugerir uma abordagem dos objetos que os considera como não-problemáticos e pressupõe um significado constante e compartilhado; tornam-se "fixos, abstratos e absolutos" (Fine, 2003, p. 465), e a fonte de perigo está na continuidade nominal fornecida pelos conceitos ostensivamente "iguais", como nos alerta Smith. O pressuposto/a aceitação dos "-ismos" significa que o entendimento das mudanças trazidas pela globalização pode ser refratado pelas lentes de concepções não problemáticas de nacionalismo, estadismo e educacionismo, mesmo se essas próprias mudanças alteram a significação de Estados-naçôes e sistemas educacionais ou o trabalho que realizaram e, logo, solapam a sua validade.

Resumindo, o nacionalismo metodológico vê o Estado-nação como o receptáculo da "sociedade", de modo que comparar sociedades significa comparar Estados-naçóes (Beck, 2002; Beck \& Sznaider, 2006). Atua tanto para o Estado-nação quanto a respeito dele, a tal ponto que a única realidade que conseguimos descrever de maneira abrangente, estatisticamente, é nacional ou, no melhor dos casos, internacional (Dale, 2005). O terceiro elemento do problema surge da tendência a justapor um nacionalismo metodológico não reconstruído a concepções não especificadas da "globalização" numa relação de soma zero. Como dissemos anteriormente, esses pressupostos "ou/ou" levam tipicamente à forma do global "que afeta" o nacional, ou ao nacional "que medeia” o global. Isso não significa que essas relações não estejam presentes, mas que não devem ser tomadas como norma.

Se o nacionalismo metodológico remete à tendência a tomar o Estado-nação como o receptáculo das sociedades, o termo relacionado, embora consideravelmente menos reconhecido (o estadismo metodológico), remete à tendência a assumir que existe uma forma particular intrínseca a todos os Estados. Ou seja, significa partir do princípio de que todas as políticas são regidas, organizadas e administradas 
essencialmente da mesma maneira, com o mesmo conjunto de problemas e de responsabilidades, e através do mesmo conjunto de instituições. O problema é que o Estado, enquanto objeto de análise, existe tanto como força material quanto como construto ideológico (Mitchell, 1999). O construto ideológico tende a dominar e espalhar-se, por exemplo, através de intervenções globais como a agenda de "boa governança" (Weiss, 2000). Além desse problema, como mostra Bourdieu (1999, p. 53), há, para o analista, os que surgem quando categorias são produzidas pelo Estado e estão também profundamente ancoradas nas sociedades. Assim, "tentar pensar o Estado é correr o risco de assumir um pensamento do Estado (ou ser submerso por ele), isto é, aplicar ao Estado categorias de pensamento produzidas e garantidas por ele e, consequentemente, deixar de reconhecer a sua verdade mais profunda”.

Vemos isso na maneira como um dado conjunto de instituições é considerado como normal, como $o$ padrão para dirigir sociedades, pois é o único encontrado no Ocidente no século Xx, e em particular no Estado-providência social-democrata que impregnou a Europa ocidental na segunda metade desse século (ver Zurn \& Leibfried, 2005). $\mathrm{O}$ que havia de central (e, poderíamos acrescentar, de único) nesta concepção era que as quatro dimensões do Estado distinguidas por Zurn e Leibfried (recursos, lei, legitimidade e bem-estar) convergiam em constelaçôes e instituiçôes nacionais. $\mathrm{O}$ que os autores deixam claro, contudo, é que "(...) as mudanças nos últimos 40 anos não são meros vincos no tecido do Estado-nação, mas, antes, um desfibramento da constelação nacional da sua época áurea” (idem, ibid., p. 1). Em outras palavras, tanto o pressuposto de um conjunto de responsabilidades comuns e de um meio de assumi-las quanto o pressuposto de que são, necessária mais do que contingentemente, associadas umas às outras não podem mais ser sustentados fora de um estatismo metodológico contínuo. E, ao mesmo tempo, este exemplo ilustra muito bem o "fetichismo institucional".

Podemos indicar mais dois pressupostos do estatismo metodológico nas ciências sociais em geral e na educação em particular: o primeiro é o reconhecimento da sua especificidade locacional como base do estatismo metodológico. $\mathrm{O}$ modelo de Estado que passou a ser aceito no discurso acadêmico, na maioria das ciências sociais, nunca foi estabelecido ou presente na maior parte daquilo que chamamos de países em desenvolvimento. Aquele modelo foi não apenas imposto na 
maioria dos Estados pós-coloniais criados depois da Segunda Guerra Mundial, mas a sua aceitação formal e o apego a ele tornaram-se a principal base de pertencimento à "comunidade internacional". Como Ferguson e Gupta (2002), entre outros, mostraram, esse modelo de Estado nunca foi um meio eficiente de conceber como a maioria das sociedades em desenvolvimento era regida. Essa representação de governo e, com ela, essa soberania da regra, impostas politicamente, têm distorcido tentativas de introduzir formas de governo justas, eficazes e eficientes naqueles países; e sua aceitação como uma descrição válida e precisa, tanto por acadêmicos quanto por políticos, baseados no fato de que um mesmo termo significava a mesma coisa, independentemente das circunstâncias, tem igualmente distorcido as análises da governança dos países em desenvolvimento.

A profundidade de penetração desses tipos de pressupostos nas ciências sociais, no que diz respeito à educação e ao desenvolvimento internacional, é resumida por Ruggie (1993, p. 143) como expondo “(...) uma mentalidade extraordinariamente empobrecida (...) capaz de visualizar desafios de longo prazo para o sistema de Estados, apenas em termos de entidades que podem institucionalmente substituir o Estado”. Nosso ponto aqui não é propor que o Estado, enquanto ator, não tem importância. Ele tem sido e continua sendo um conjunto de instituiçóes muito expressivo e poderoso, capaz de mobilizar poder e ação. Preferimos focar, primeiro, no modo como a ideia do Estado se representa como uma forma universal em vez de uma representação particular que foi universalizada e, segundo, no modo como o próprio Estado, enquanto projeto e receptáculo de poder, tem escapado a um exame intelectual minucioso e aprofundado.

A principal conclusão que se deve tirar dessa breve discussão é que uma base essencial para qualquer resposta por parte dos pesquisadores da educação para entender os processos da globalização é reconhecer que usar "o Estado" como conceito explicativo, sem maior qualificação, significa ao mesmo tempo aceitar uma imagem imprecisa do mundo e perpetuar um determinado resultado de imposição política. Em suma: uma consequência da globalização para a sociologia da educação, e para as ciências sociais em geral, é deixar claro que o Estadonação deveria ser considerado como explanandum, o que deve ser explicado, mais do que como explanans, parte de uma explicação. Em outras palavras, os componentes do que é conotado por Estado-nação 
precisam ser "desagregados" e o seu status e as suas relaçôes, examinados de novo, num mundo globalizado, tanto por pedagogos comparatistas quanto por outros cientistas sociais.

Podemos ilustrar esses pontos ao reconhecer que o Estado nacional não é mais o único ator na área da educação, nem necessariamente o mais importante ou evidente. Obviamente, como argumentou Chernilo (2006), o que se deve explicar é como o Estado conseguiu se representar enquanto lugar primário de poder e receptáculo dessas relaçóes sociais, inclusive a educação enquanto geometria particular de atividades, quando pesquisas empíricas poderiam nos dizer que não era o caso. Além disso, concretamente, podemos ver que, se for analisada de perto a governança educacional (isto é, as combinações e a coordenação de atividades, atores/agentes, e escalas através das quais a "educação" é construída e ministrada nas sociedades nacionais), é possível identificar quatro categorias de atividades que, coletivamente, compõem a governança educacional (que, por razões de exposição, são consideradas como mutuamente excludentes e coletivamente exaustivas): financiamento; fornecimento ou oferta; propriedade; regulação. Essas atividades podem, em princípio (assim como são na prática), ser desempenhadas independentemente umas das outras por uma série de agentes outros que não o Estado (embora este continue sendo um possível agente da governança educacional num amplo conjunto de escalas, do local ao global).

O diagrama também reflete o argumento ora exposto de que não é nem "natural" nem essencial que todas essas atividades sejam realizadas pelo Estado, ou por qualquer outro órgão único. Antes, podem ser realizadas por qualquer um do amplo leque de agentes indicados: Estado, mercado, comunidade e lar, separadamente ou juntos. E é o que entendemos por governança aqui: a coordenação de coordenação. A outra característica do diagrama é que podemos reconhecer que essas funções também podem ser desempenhadas em várias escalas diferentes; não estão confinadas nem ao nacional nem ao Estado. Logo, o diagrama visa a ajudar a reconhecer que a governança educacional tem uma natureza multiescalar e que as políticas educacionais não podem mais ser vistas como reserva exclusiva de Estados-nações individuais, e a indicar uma base para enfrentar e entender mais claramente a consequência disso. E se prestarmos mesmo atenção aos argumentos de que a relação entre as escalas global e nacional (e subnacional) não é um jogo 
de soma nula, somos levados a esperar algum tipo de divisão do trabalho entre escalas e a procurá-la. Além disso, o diagrama também ilustra o argumento de que as atividades de governança não incluem um todo homogêneo, mas podem ser esmiuçadas nas categorias citadas. Consequentemente, podemos esperar uma divisão de trabalho funcional tanto quanto escalar. Portanto, isso significa, em poucas palavras, que qualquer redimensionamento da governança das políticas educacionais tende a ser seletivo relativamente aos problemas centrais da educação. Assim, podemos esperar que as atividades de sistemas educacionais que estão relacionadas aos elementos predominantemente "nacionais" de integração do capitalismo, tal como coesão (ordem social + identidade nacional) e legitimação societais, que incluem uma parte maior das políticas e dos processos que têm tradicionalmente preocupado os sistemas educacionais, continuem sendo exercidas em nível nacional, embora num contexto alterado pelo poder de "modelagem" das organizações internacionais. Por outro lado, podemos também esperar que, numa era da Economia do Conhecimento supranacional e de reduzida importância das economias "nacionais", algumas das atividades educacionais associadas com o apoio à acumulação sejam cada vez mais governadas num nível supranacional, em resposta à "agenda globalmente estruturada para a educação". Contudo, mesmo aqui, como já sugerimos, não deveríamos partir do princípio de que os Estados nacionais e os governos não vão desempenhar papel algum: vão necessariamente estar envolvidos na interpretação e na tradução das consequências das "regras" modeladoras das organizações internacionais, em formas e prioridades nacionalmente apropriadas.

Um exemplo do tipo de teorizaçôes possibilitadas pelo reconhecimento do nacionalismo metodológico e do estadismo e pelo fato de evitá-lo é conceber "a educação" não como necessária e exclusivamente associada ao Estado-nação, mas como constituída através dos funcionamentos complexos das divisóes funcional e escalar do trabalho de governança educacional (ver Dale, 2003), o que significa de qualquer um ou todos entre um único locus de governança, loci paralelos de governança em diferentes escalas, ou formas híbridas de governança entre escalas e/ou atividades e/ou agentes. Por exemplo, desde a reestruturação do setor educacional no Reino Unido e o surgimento de novos processos de regionalismo europeu, importantes aspectos da governança educacional estão hoje em dia separados do subnacional e foram 
reconstituídos em escalas nacional e europeia e reintroduzidos nas escolas. Então, o que se costuma entender por governança, nesse caso, é a substituição do pressuposto de que o Estado governa sempre e necessariamente a educação através do controle de todas as atividades de governo, pelo que se pode chamar de coordenação da coordenação, com o Estado despenhando possivelmente o papel de coordenador ou regulador de último recurso.

Na superfície, "a educação" pareceria ser o mais constante dos três componentes que estamos examinando. Afinal de contas, todos neste mundo já foram ou terão a oportunidade de ir à escola (o que, de modo interessante, é definição da educação nos Objetivos de Desenvolvimento do Milênio). Contudo, também sabemos que o que se entende por educação difere amplamente e segundo muitas dimensôes, e que a experiência da escolaridade varia enormemente. Mais precisamente, o que chamamos de "educacionismo" remete à tendência a considerar "a educação" como uma única categoria para fins de análise, com um escopo comum presumido e um conjunto de saberes, práticas e pressupostos implicitamente compartilhados. Isto ocorre quando a educação é tratada como abstrata, fixa, absoluta, anistórica e universal, quando não se distingue o seu uso para descrever objetivo, processo, prática e resultados. Representações particulares da educação são tratadas isoladamente umas das outras e enfrentadas discretamente, não como parte de um conjunto mais amplo de representações (pois não há sugestão de que as diferentes representações da educação nada têm em comuns entre si ou que cada etiqueta é colada aleatoriamente). Longe disso, é o reconhecimento de que existem relações cruciais entre diferentes representações da educação, que estão sendo ocluídas ou disfarçadas pelo fracasso em distinguilas, que torna tão importante identificar o educacionismo e buscar ultrapassá-lo. O educacionismo não discrimina os usos do termo nem os torna problemáticos, o que praticamente impede que "a educação" seja um objeto de comparação.

O outro problema principal com a relativa ausência de trabalhos que problematizem "a educação" (agora entre aspas) - com isto quero perguntar como instituiçôes, organizaçōes, práticas particulares se tornaram o que são, e o que se pode aprender com isso - é que existe pouco incentivo para interrogar o que conta enquanto educação, o que queremos dizer quando usamos o termo. De fato, se, hoje 
em dia, perguntasse isso aos que me leem, com certeza conseguiria múltiplas definições da educação que seriam suficientemente diferentes entre si, para que seja extremamente difícil compará-las ou mesmo agregá-las de forma significativa. Poderíamos descartar algumas, mas, mesmo assim, continuaríamos tendo profundas e sérias diferenças entre elas, por exemplo, entre a educação como processo ou resultado, como "uma” educação, como prática, como instituição, como algo produzido ativamente em instituiçôes dedicadas, e como algo "absorvido" à medida que passamos pela vida. Obviamente, podemos rapidamente superar muitos desses problemas com um pouco de senso comum, mas, de novo, quando vemos a educação como um assunto sério (geralmente o mais sério) em que podemos nos envolver, diferenças reais e complexas permanecem, especialmente, é claro, quando não reconhecemos que não estamos falando da mesma coisa.

\section{Problematizar a “educação” através das Questões de Educação}

Parece claro, então, que, se quisermos que a sociologia da educação retenha uma possibilidade de oferecer tanto críticas quanto comentários numa era de globalização, precisamos tentar desenvolver ferramentas que ultrapassem os "-ismos" metodológicos, mais particularmente o "educacionismo", e permitam diferentes compreensões da educação, mensuráveis e utilmente comparáveis. Isto envolve enfrentar os principais pressupostos e bases sobre os quais a busca prematura pela "relevância" e a "utilidade" repousa, na sociologia da educação:

- A preocupação com a melhoria imediata da prática, dentro de um conjunto de pressupostos considerados como naturais sobre conhecimento, aprendizagem etc.

- O uso indiscriminado (inconsciente e irrefletido) do termo "Educação".

- O menosprezo para com a necessidade de problematizar os pressupostos do que a educação é, faz, pode ser, que a globalização tornou particularmente agudos. 
- O menosprezo para com a questão de saber como surgiram os atuais pressupostos e definições.

Proponho abordar isso não tentando refinar e definir a educação filosoficamente, mas convertendo-a em um conjunto de variáveis, na forma de grupos de perguntas, vinculadas juntas nos grupos e entre os grupos, para obter uma zona de inteligibilidade mútua (Santos, 2005) através da qual poderemos isolar questões de interesse. A meta é construir um dispositivo heurístico simples que permita abrir novos caminhos para examinar velhos problemas e gerar novas questóes.

Então, em vez de partir do princípio de que todos designamos a mesma coisa quando estamos falando de educação e aceitar esse fato, podemos colocar um conjunto de perguntas precisas que consiga fornecer uma base para uma discussão coerente. Essas questóes colocamse em quatro níveis (tanto para refletir o leque de significações que pode ser vinculado à "educação", quanto para deixar clara a complexidade das perguntas, pois nenhuma delas tem uma resposta apenas num único nível). Esses níveis são os da prática educativa ("Quem ensina? O quê? A quem? etc.”); as políticas educacionais ("como e por quem essas coisas são decididas, governadas, administradas, geridas? etc."); as políticas da educação (sobre que bases e no interesse de quem essas coisas são determinadas, controladas? Com que relações com os outros setores e escalas? etc."); e o nível de resultados ("Com que consequências públicas, particulares, pessoais? etc.”). Isto já era um problema bastante amplo antes da era da globalização, mas uma das consequências do advento da Economia do Conhecimento, por exemplo, no intento mais ou menos claro de alterar a significação, quando não o vocabulário da educação, foi uma exacerbação qualitativa do problema.

Finalmente, é preciso indicar que as Questōes de Educação ainda consideram que existe uma base nacional para a "educação", pois, empiricamente, é o nível no qual a maior parte das atividades incluídas na categoria "educação" ainda ocorre. Isto não significa adotar um foco completa ou exclusivamente nacional, contudo. Também não significa que a única ou mais importante escala de análise é a nacional, nem acarreta qualquer pressuposto de comparabilidade entre níveis nacionais; ainda é importante problematizar a comparabilidade das categorias que usamos nos níveis e escalas e entre eles. 


\begin{tabular}{|c|c|}
\hline NÍVEL & QUESTŌES DE EDUCAÇĀO \\
\hline $\begin{array}{l}\text { Nivel } 1 \\
\text { Práticas } \\
\text { Educativas }\end{array}$ & $\begin{array}{l}\text { Quem é ensinado (ou aprende através de processos explicitamente concebidos } \\
\text { para promover aprendizagem)? O que? Como? Por quê? Quando? Onde? Por/a } \\
\text { partir de quem? Em que circunstâncias imediatas e condiçōes mais amplas? } \\
\text { Com que resultados? } \\
\text { Como, por quem e para que fins isto é avaliado? }\end{array}$ \\
\hline $\begin{array}{c}\text { Nivel } 2 \\
\text { Politicas } \\
\text { Educacionais }\end{array}$ & $\begin{array}{l}\text { Como, em busca de que fins sociais, econômicos, políticos e educativos } \\
\text { manifestos e latentes; com que padrão de coordenação de governança } \\
\text { educacional; por quem; e segundo que dependências de trajetórias (path } \\
\text { dependencies) setoriais e culturais, essas são coisas problematizadas, decididas, } \\
\text { administradas, geridas? }\end{array}$ \\
\hline $\begin{array}{l}\text { Nivel } 3 \\
\text { Políticas de } \\
\text { Educação }\end{array}$ & $\begin{array}{l}\text { Problemas de "contrato social" (como a educação contribui para ele?) (valores } \\
\text { da modernidade + problemas centrais) } \\
\text { Lógica de intervenção (como a contribuição da educação deve ser ofertada?) } \\
\text { (gramática da escolaridade [Grammar of schooling] + foco nacional) } \\
\text { Quais as formas da "arquitetura da educação"? } \\
\text { De que modo os problemas centrais do capitalismo (acumulação, ordem social e } \\
\text { legitimação) se refletem no mandato, na capacidade e na governança } \\
\text { educacional? Como e em que escalas as contradições entre as soluçōes são } \\
\text { enfrentadas? } \\
\text { Como as fronteiras do "sector da educação" são definidas e como se sobrepõem } \\
\text { e se relacionam com outros setores? Como o setor da educação está relacionado } \\
\text { à cidadania e aos regimes de gêneros? } \\
\text { Como, em que escala e em que configuraçães setoriais a educação contribui } \\
\text { para a integração/estabilização extraeconômica da acumulação? } \\
\text { Qual a natureza das relaçôes dentro das escalas e entre elas e dentro dos setores e } \\
\text { entre eles (contradição, cooperação, indiferença mútua?) } \\
\text { Que divisões de trabalho funcionais, escalares e setoriais da governança } \\
\text { educacional estão implementadas? }\end{array}$ \\
\hline $\begin{array}{c}\text { Nivel } 4 \\
\text { Resultados }\end{array}$ & $\begin{array}{l}\text { Quais são os resultados individuais, particulares, públicos, coletivos e em termos } \\
\text { de comunidade da "educação" em cada nível escalar? Quais são as suas } \\
\text { consequências para a equidade, a democracia e a justiça social? }\end{array}$ \\
\hline
\end{tabular}

\section{Conclusão}

Neste artigo comecei a lançar alguma luz sobre a relação entre a globalização e a educação, por meio de uma reavaliação da relação entre concepções da globalização e da educação e das ferramentas analíticas de que precisamos para examiná-la efetivamente. $\mathrm{O}$ argumento fundamental foi que não podemos entender os problemas da pósmodernidade com as ferramentas da modernidade, e tentei ilustrar 
isto revisitando um trabalho da pré-globalização que priorizava o papel do Estado nas políticas educacionais. Esta análise baseia-se na premissa de que a globalização representa uma ruptura, não uma continuidade, com o que ocorria antes. Argumentei que a globalização acarreta uma abordagem diferente do que entendemos por nacional, educação e sistemas, alegando que continuar a vê-los segundo modos apropriados vinte anos atrás significa fixar e fetichizar aquelas concepções, e reduzir as abordagens aos "-ismos" metodológicos aqui discutidos, sendo o estatismo metodológico o mais importante deles, neste contexto.

A mudança de ênfase e de expectativas da educação sob a ordenação neoliberal dos problemas centrais criou desafios completamente novos e distintos para a educação. Estes parecem não poder ser enfrentados facilmente através de formas de escolaridade que vingavam vinte anos atrás. Um fluxo de documentos de organizações internacionais enfatiza a necessidade de mudanças radicais, por exemplo, de "ensino para aprendizagem" no cerne do empreendimento educacional, uma mudança de conteúdo para competências (mais particularmente o programa PISA) e a necessidade de aprendizagem ao longo da vida. Ou seja, a educação tal como ofertada e praticada sob as condições da modernidade não é suficiente para as exigências do presente e deve ser radicalmente reformada.

Logo, o modo mais apropriado de concluir este artigo é considerar em que pé se encontram os argumentos de The State and education policy vinte anos depois. No que diz respeito à proeminência dos problemas centrais, estes se sustentam muito bem e ainda são parte da agenda fundamental, mas as mudanças na sua composição, brevemente descritas aqui, tiveram implicaçôes centrais para as maneiras como moldam a educação e as direçôes que lhe dão. O Estado é ainda uma característica proeminente no cenário das políticas educacionais, mas, mais uma vez, como tentei mostrar neste artigo, não é o "mesmo" Estado que aquele sobre o qual escrevi vinte anos atrás, e as reivindicações que então havia feito não são mais viáveis sob a globalização neoliberal. Talvez a mais importante diferença seja que o Estado não pode mais ser visto como um explanans, como o fatorchave para entender as políticas educacionais, mas como um explanandum, o que deve ser explicado. Nisso, pode ser visto como um exemplo valioso da necessidade de repensar e re-equipar a caixa de 
ferramentas da sociologia da educação após a globalização. Junto com esta mudança na natureza do Estado, houve uma mudança no que deve ser entendido por "políticas educacionais". Isso pode estar refletido na natureza mudável das significações nos níveis 2 e 3 das Questôes de Educação e nas relações entre estes níveis, o que gira em torno das concepções da "governança" (da natureza e das fronteiras variáveis) e do "sector" da educação (ver Dale, 2007), respectivamente.

Finalmente, sugeri que um modo possivelmente eficiente de superar as dificuldades envolvidas para "entender" de novo alguma coisa que era tão "óbvia" para nós, e que não precisava de "compreensão" (o que foi o principal obstáculo aos progressos nas teorizaçôes da educação, de modo mais geral), consiste em reconhecer que o uso de novas ferramentas - que, embora não "substituam" realmente as existentes, baseiam-se em reconceituações radicais - deve nos permitir continuar a servir um objetivo teórico útil e nos oferecer um meio valioso de continuar a construir uma análise crítica da "educação".

Recebido em janeiro de 2010 e aprovado em fevereiro de 2010.

\section{Nota}

1. N. do T.: ao longo do texto, o autor distingue "Education policy" (aqui traduzido por "políticas educacionais") de "Politics of education" (aqui traduzido por "políticas de educação"). Como tanto "policy" quanto "politics" se traduzem por "política(s)", fica impossível marcar esta diferença em português. Segundo o autor, o primeiro "refere-se ao processo de tomada de decisōes diretas, no cotidiano, e aos seus resultados imediatos (textos políticos, por exemplo), ao passo que o segundo designa os processos e as estruturas que enquadram as agendas de 'políticas educacionais' e as dirigem. As 'políticas de educação' também poderiam ser chamadas de "economia política de educação".

\section{Referências}

BECK, U. The cosmopolitan society and its enemies. Theory, Culture and Society, London, v. 19, n. 1-2, p. 17-44, 2002.

BECK, U.; SZNAIDER, N. Unpacking cosmopolitanism for the social sciences: a research agenda. The British Journal of Sociology, London, v. 57, n. 1, p. 1-23, 2006.

BOURDIEU, P. Rethinking the State: genesis and structure of the bureaucratic field. In: Steinmetz, G. (Ed.). State/culture: State 
formation after the cultural turn. Ithaca: Cornell University, 1999. p. 53.

CAMMACK, P. "Signs of the times": capitalism, competitiveness, and the new face of empire in Latin America. In: PANITCH, L.; LeYs, C. (Ed.). The empire reloaded: socialist register 2005. London: Merlin, 2004.

CHERNILO, D. Methodological nationalism and its critique. In: Delanty, G.; Kumar, K. (Ed.). The Sage handbook of nations and nationalism. London: Sage, 2006. p. 129-140.

DALE, R. The State and education policy. Milton Keynes: Open University, 1989.

DALE, R. The State and the governance of education: an analysis of the restructuring of the state-education relationship. In: Halsey, A. et al. (Ed.). Education, culture, economy and society. Oxford: Oxford University, 1997.

DALE, R. The Lisbon Declaration: the reconceptualisation of governance and the reconfiguration of the European education space. Paper presented to the RAPPE Seminar, "Governance, Regulation and Equity in European Education Systems". London: Institute of Education, 20 Mar. 2003.

DALE, R. Globalisation, knowledge and comparative education. Comparative Education, Chicago, v. 41, n. 2, p. 117-150, 2005.

DALE, R. The EU's lifelong learning strategy and the reshaping of the education sector. Paper presented at Keele University, May 22007.

DALE, R.; ROBERTSON, S. Beyond 'isms' in comparative education in an era of globalisation: political and methodological reflections. In: Kazamias, A.; Cowan, R. (Ed.). Handbook on comparative education. Netherlands: Springer, 2007.

FERGUSON, J.; GUPTA, A. Spatializing States: toward an ethnography of neoliberal governmentality. American Ethnologist, Davies, v. 29, n. 4, p. 981-1002, 2002.

FINE, R. Taking the 'Ism' out of cosmopolitanism: an essay in reconstruction. European Journal of Social Theory, v. 6, n. 4, p. 451470, 2003. 
GILL, S. The emerging world order and European change: the political economy of European Union. In: Miliband, R. (Ed.). Socialist Register 1992. London: Merlin Press, 1992. p. 157-196.

MITCHELL, T. State, economy and the State effect. In: Steinmetz, G. (Ed.). State/culture: State formation after the cultural turn. Ithaca: Cornell University, 1999.

RUGGIE, J.G. Territoriality and beyond: problematizing modernity in international relations. International Organization, Cambridge, UK, v. 47, n. 1, p. 139-74, 1993.

SANTOS, B.S. Towards a new legal common sense. London: Butterworth, 2002.

SANTOS, B.S. The future of the world social forum: the work of translation. Development, v. 48, n. 2, p. 15-22, 2005.

SMITH, G. When "the logic of capital is the real which lurks in the background" programme and practice in European regional economies. Current Anthropology, Chicago, v. 47, n. 4, p. 621-639, 2006.

UNGER, R.M. Democracy realized: the progressive alternative. London: Verso, 1998.

WEISS, T.G. Governance, good governance and global governance: conceptual and actual challenges. Third World Quarterly, v. 21, n. 5, p. 795-814, 2000.

ZURN, M.; LEIBFRIED, S. Reconfiguring the national constellation. European Review, Cambridge, UK, n. 13, p. 1-36, 2005. 